The mean (SEM) length of stay in hospital was $23.9(3 \cdot 3)$ hours in the control group and $24 \cdot 5(2 \cdot 5)$ hours in the treatment group. Fourteen $(78 \%)$ of those in the control group and $14(74 \%)$ of those in the treatment group required oral steroids. Only one child (in the treatment group) required intravenous aminophylline, 15 hours after his admission and six hours after his second dose of ipratropium.

\section{Discussion}

Sixteen out of 37 children scored 13 or more on admission and 17 out of 19 children had a peak expiratory flow rate below $50 \%$ of the expected value. Nevertheless, we were unable to show significant benefit from the sequential use of nebulised ipratropium in addition to salbutamol. Therefore, although it may be valuable in individual children, the routine use of ipratropium in acute asthma cannot be recommended.

We thank Dr E J Hiller and Dr D A Curnock for allowing us to study their patients, the pharmacy department at the City Hospital for preparing the solutions, and the nursing staff of Papplewick Ward.

\section{References}

1 Mann NP, Hiller EJ. Ipratropium bromide in children with asthma. Thorax 1982;37:72-4.

${ }^{2}$ Groggins RC, Milner AD, Stokes GM. Bronchodilator effects of clemastine, ipratropium bromide and salbutamol in preschool children with asthma. Arch Dis Child 1981;56:342-4.

${ }^{3}$ Davis A, Vickerson F, Worsley G, Mindorff C, Kazim F, Levison $\mathrm{H}$. Determination of dose response relationship for nebulised ipratropium in asthmatic children. J Pediatr 1984;105: $1002-5$.

+ Storr J, Lenney W. Nebulised ipratropium and salbutamol in asthma. Arch Dis Child 1986;61:602-3.

5 Beck R, Robertson C, Galdes-Sebaldt M, Levison H. Combined salbutamol and ipratropium bromide by inhalation in the treatment of severe, acute asthma. J Pediatr 1985;107:605-8.

${ }^{6}$ Ward MJ, Fentem PH, Roderick-Smith WH, Davies D. Ipratropium bromide in acute asthma. $B r$ Med $J$ 1981;282: 598-600.

Correspondence to Dr R J Rayner, City Hospital, Hucknall Road, Nottingham NG5 1PB.

Received 19 February 1987

\title{
Prader-Willi syndrome in siblings, due to unbalanced translocation between chromosomes 15 and 22
}

\author{
F FERNANDEZ, C BERRY, AND D MUTTON
}

High Wycombe General Hospital and South East Thames Regional Genetics Centre, Guy's Hospital, London

SUMMARY In a family in which the father carried a balanced translocation between chromosomes 15 and 22 two of his children had Prader-Willi syndrome and an unbalanced chromosome complement, having lost the proximal bands from the long arm of chromosome 15 . His four other surviving children were normal but carried a balanced translocation.

\section{Case report}

The proband, who was 5 years old at the time of writing, was admitted to the special care baby unit when 3 days old with extreme hypotonia and feeding difficulties. He had been born to a consanguineous Asian couple and was the product of an uneventful pregnancy that had progressed to term; he had been delivered vaginally. Birth weight was $2020 \mathrm{~g}$, and he appeared otherwise normal apart from bilaterally undescended testes and a small scrotum. Tube feeding was necessary for two months. His development was delayed both physically and mentally: he walked at the age of $31 / 2$ and attended a special school for the educationally subnormal.

His next younger sibling had identical problems and was managed in the special care baby unit from the age of 5 days. He also was tube fed for two months. At over 1 year old he had a developmental age of 9 months and hypogonadism.

The family details are shown as a pedigree in Figure 1.

\section{Cytogenetics}

The proband was found to have a deletion of chromosome 15 during a study of children diagnosed as having Prader-Willi syndrome. ${ }^{1}$ In this study high resolution $G$ banding and Distamycin/DAPI fluorescence were used. ${ }^{2}$ This technique is valuable for defining the intense fluorescence that is characteristic of the short arms of chromosome 15.

There was no intense fluorescence on the short 


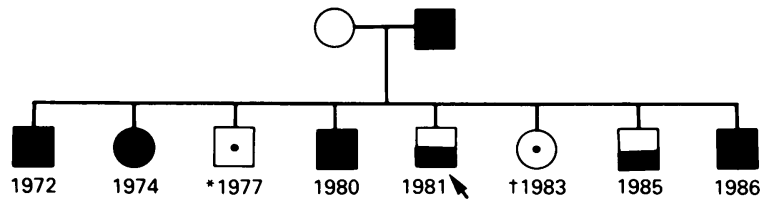

Balanced translocation, $\mathrm{t}(15,22)$

Prader-Willi syndrome with unbalanced karvotype (der 22)

- No karyotypic analysis-neonatal deaths

Normal karyotype

arms of the deleted chromosome 15 , and it was thought, therefore, that this might be attributable to a translocation between two acrocentric chromosomes. Chromosome studies of blood from the parents confirmed that the father carried a balanced translocation, $t(15 ; 22)(q 13 ; q 112)$ (Figure 2a). The two siblings with the syndrome were effectively monosomic for the short arm and proximal long arm of chromosome 15 and trisomic for the short arm and proximal region of chromosome 22 (Figure 2b).
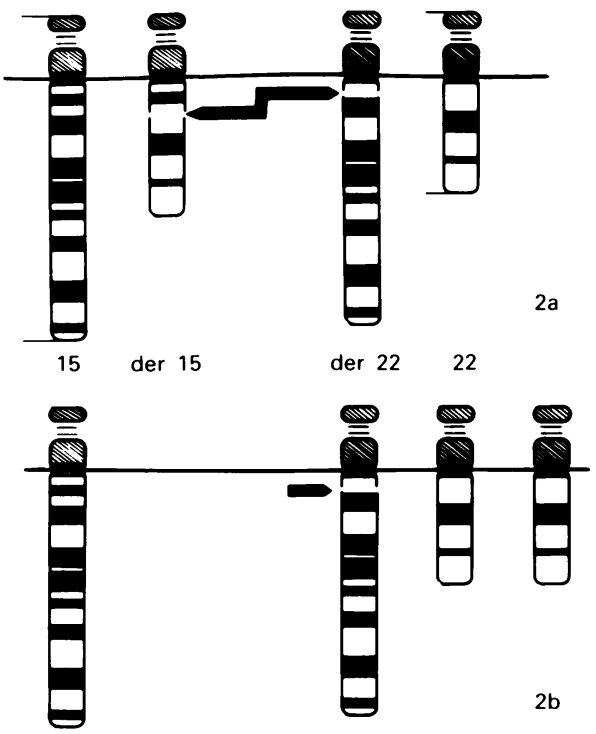

Fig. 2 (a) Partial idiogram of balanced translocation in the father, $46 X Y, t(15 ; 22)(q 13 ; q 12)$; (b) idiogram of unbalanced chromosomes of affected children, $46 X Y,-15$, + der (22). They are monosomic for short arm and proximal long arm of chromosome 15 and trisomic for short arm and centromeric region of chromosome 22 .
Fig. 1 Pedigree showing chromosome results. ${ }^{*}$ Death at one week, cause unknown. +Stillbirth due to hydrocephalus.
The surviving siblings carried the balanced translocation. Studies were not done on the two infants who died in the perinatal period. This was unfortunate as the segregation ratio here was unusual with all six karyotyped children carrying the paternal translocation in either a balanced or an unbalanced form.

\section{Discussion}

Prader-Willi syndrome in siblings is rare. ${ }^{3}$ After Hawkey and Smithies described a child with this syndrome and a translocation involving chromosome $15^{4}$ many abnormalities of chromosome 15 with Prader-Willi syndrome have been reported; a small interstitial deletion of $15 \mathrm{q} 112$ is the most consistent finding. Butler et al reviewed the clinical and cytogenetic findings. 5

Only about half of all cases can be diagnosed from chromosomal analyses. The finding of normal chromosomes does not rule out the possibility of Prader-Willi syndrome. In our case a previously unreported chromosomal abnormality was present and hence helped the diagnosis in both the affected and the carrier siblings.

Early diagnosis and counselling helped the parents understand the need for dietary control in the affected children. The proband did not put on a large amount of weight and was just on the third weight percentile for his age. The parents' religious beliefs precluded preventing the birth of further affected children, but, clearly, genetic counselling of the siblings carrying the translocation will be important.

We thank Dr K C Cheetham, consultant paediatrician, Wycombe General Hospital, who kindly permitted use of his notes and Dr J A Jonasson, department of cytogenetics, Oxford, for the cytogenetic information on the younger children; thanks are also due to Dr B Laurance, who gave constructive criticism, and Claudine Fear for her cytogenetic help. 


\section{References}

' Fear CN, Mutton DE, Berry AC, Heckmatt JZ. Dubowitz V Chromosome 15 in Prader-Willi syndrome. Dev Med Chila Neurol 1985;27:305-11.

2 Schweizer D. Ambros P. Andrle M. Modification of DAPI binding on human chromosomes by prestaining with a DNAbinding oligopeptide antibiotic, Disamycin A. Exp Cell Res 1978;111:327-32

${ }^{3}$ Clarren SK, Smith DW. Prader-Willi syndrome-variable severity and recurrence risk. Am J Dis Child 1977;131:798-800.
${ }^{4}$ Hawkey CJ, Smithies A. The Prader-Willi syndrome with a $15 / 15$ translocation - case report and review of the literature. J Med Genet 1976;13:152-7.

5 Butler MG, Meaney FJ, Palmer CG. Clinical and cytogenetic survey of 39 individuals with Prader-Labhart-Willi syndrome. Am J Med Genet 1986;23:793-809.

Correspondence to Mr D Mutton, South East Thames Regional Genetics Centre, Guy’s Tower, Guy’s Hospital, London SE1 9RT.

Received 18 December 1986

\title{
Green or blue light phototherapy for neonates with hyperbilirubinaemia
}

\author{
H AYYASH, E HADJIGEORGIOU, I SOFATZIS, H DELLAGRAMMATICAS, AND \\ E SIDERIS
}

2nd Department of Paediatrics, University of Athens, Leto and M. Eliades Maternity Hospitals, Athens, and Biology Division N.R.C. 'Democritos', Athens, Greece

SUMmary A total of 262 neonates were treated with green $(350-650 \mathrm{~nm})$ or blue $(300-600 \mathrm{~nm})$ light phototherapy for a similar length of time. There was no significant difference in the rate of bilirubin photodegradation between the groups.

The possibility of using equally effective but safer spectral areas than the conventional $420-490 \mathrm{~nm}$ (blue part of the spectrum), in the treatment of neonatal jaundice is currently being investigated. It has been shown that green light is more effective than white in reducing serum bilirubin concentrations in preterm neonates. ${ }^{1}$

The purpose of the present study was to evaluate the efficacy of green versus blue light in reducing serum bilirubin in term and preterm neonates with hyperbilirubinaemia.

\section{Patients and methods}

Standard 20 watt sylvania F20T12G (green) or F20T12B (blue) fluorescent tubes were mounted on to conventional phototherapy units with five tubes each to provide the light source. The emission spectra were estimated with a Baush-Lomb 250 monochromator. The radiance of the lamps was measured from $50 \mathrm{~cm}$ away with a research IL 700 radiometer. The integrated emission energy was 0.326 milliwatt for the green light and 0.261 milliwatt for the blue light. A total of 262 neonates with jaundice of unknown aetiology were included, overt haemolysis having been excluded. They were separated into two groups according to their gestational age; 200 were born at term ( $\geqslant 37$ weeks) and 62 before term ( $<37$ weeks). They were then randomly allocated into two subgroups to receive either green or blue phototherapy (Table 1).

Table 1 Clinical and laboratory characteristics of the neonates

\begin{tabular}{|c|c|c|c|c|}
\hline \multirow[t]{2}{*}{ Characteristics } & \multicolumn{2}{|c|}{ Full term neonates } & \multicolumn{2}{|c|}{ Preterm neonates } \\
\hline & $\begin{array}{l}\text { Green light } \\
(n=100)\end{array}$ & $\begin{array}{l}\text { Blue light } \\
(n=100)\end{array}$ & $\begin{array}{l}\text { Green light } \\
(n=31)\end{array}$ & $\begin{array}{l}\text { Blue light } \\
(n=31)\end{array}$ \\
\hline Gestational age (weeks) & $38 \cdot 88(0 \cdot 131)$ & $38.99(0.127)$ & $34 \cdot 70(0 \cdot 374)$ & $34.58(0 \cdot 340)$ \\
\hline Birth weight $(\mathrm{g})$ & $3391(43)$ & $3397(44)$ & $2418(90)$ & $2304(80)$ \\
\hline $1 / 2$ body surface $\left(\mathrm{cm}^{2}\right)$ & $1063(12 \cdot 7)$ & $1055(9 \cdot 2)$ & $838(25 \cdot 5)$ & $832(20 \cdot 5)$ \\
\hline Age at the start of phototherapy (hours) & $105 \cdot(0)(2 \cdot 62)$ & $98.53(3.09)$ & $87.45(4.93)$ & $83.73(5 \cdot 52)$ \\
\hline Duration of phototherapy (hours) & $42.68(2 \cdot 74)$ & $49 \cdot 88(3 \cdot(2)$ & $53 \cdot 26(5 \cdot 52)$ & $53.29(5.90)$ \\
\hline
\end{tabular}

Values are given as mean (SD): none of the differences were significant at the $5 \%$ level 